\title{
OLASILIK TABANLI YAKLAŞIM KULLANARAK METAL ŞEKİLLENDİRME ISŞLEMİNDE GERI YAYLANMA, BURUŞMA VE İNCELME PROBLEMİNİ EN AZA İNDİRECEK YENİ BİR TASARIM METODOLOJİSI
}

Oğuz KAYABAŞı ${ }^{*}$

Düzce Üniversitesi, Mühendislik Fakültesi, Biyomedikal Mühendisliği Bölümü, Düzce, Türkiye

\begin{tabular}{l} 
Anahtar Kelimeler \\
\hline Metal Șekillendirme, \\
Optimizasyon Teknikleri, \\
Sonlu Elemanlar Analizi, \\
Monte Carlo Simülasyonu.
\end{tabular}

\section{A NOVEL DESIGN TO MINIMIZE SPRINBACK, WRINKLING AND THICKNESS REDUCTION PROBLEM IN SHEET METAL FORMING PROCESS USING PROBABILISTIC APPROACH}

\begin{abstract}
Öz
Saç metal prosesinde, geri yaylanma, buruşma ve kalınlık azalması en yaygın sorunlardan biri haline gelmiştir. Bu çalışmada, otomobil yan panelinde geri yaylanma, buruşma ve kalınlık azalmasını en aza indirmek için üç yaklaşım önerilmiştir. İlk yaklaşımda, çift pot çemberi kullanılmasının geri yaylanma, buruşma ve kalınlık azaltma üzerindeki etkisi incelenmiştir. İkinci yaklaşımda, otomobil panelinin șekillendirilebilirliğinin daha da iyileștirilmesinde optimizasyon yönteminin kullanımı incelenmiştir. Optimizasyon yöntemiyle, en uygun şekillendirme özellikleri için şekillendirme işlemi parametrelerinin en uygun değerleri hesaplanmıştır. Optimum değerleri bulmada Sonlu Elemanlar Analizi, Tepki Yüzey Metodolojisi ve Genetik Algoritma birleştirilmiştir. Etkili entegrasyon sağlamak için bir bilgisayar programı yazılmıștır. Bu çalışma çift pot çemberininin kullanımı biçimlendirilebilirliği önemli ölçüde arttırdığı gözlenmiștir. Üçüncü yaklaşımda olasılıksal tasarım yöntemi Monte Carlo Simülasyonu, otomatik bir tasarım aracı oluşturmak için entegre edilmiştir, Sonuçların güvenilirliği, olasılıksal tasarım teknikleri kullanılarak kontrol edilmiş ve iyileştirilmiştir.
\end{abstract}

\section{Keywords}

Sheet Metal Forming,

Optimization Techniques,

Finite Element Analysis,

Monte Carlo Simulation.

\begin{abstract}
In the sheet metal process, springback, wrinkling and thickness reduction have become one of the most common problems. In this study, three approaches are proposed to minimize springback, wrinkling and thickness reduction for automobile side panel, In the first approach, the effect of using double binder on springback, wrinkling and thickness reduction is studied, In the second approach, the use of optimization method in further improving formability of the automobile panel is investigated, With the optimization method, the most appropriate values of forming process parameters are calculated for optimum formability characteristics, Positions of the upper die and draw-bead, draw-bead radius, forces applied on the upper die surface and double binder surfaces are considered as process parameters, In finding optimum values, Finite Element Analysis, Response Surface Methodology and Genetic Algorithm are integrated, To achieve efficient and effective integration, a computer program is written, From this study it is observed that double binder with an appropriate stamping force improves formability significantly, Application of optimization method also improves further formability characteristics of the automobile panel, In the third approach probabilistic design method Monte Carlo Simulation are integrated to create an automated design tool, The reliability of the results are checked and refined by using probabilistic design techniques
\end{abstract}

\section{Alıntı / Cite}

Kayabașı, O. (2020). Olasılık Tabanlı Yaklașım Kullanarak Metal Șekillendirme İșleminde Geri Yaylanma, Buruşma Ve İncelme Problemini En Aza İndirecek Yeni Bir Tasarım Metodolojisi, Mühendislik Bilimleri ve Tasarım Dergisi, 8(1), 198-209.

\footnotetext{
* ilgili yazar / Corresponding author: oguzkayabasi@duzce.edu.tr, +90-380-542-1036
} 


\begin{tabular}{l|l|l}
\hline Yazar Kimliği / Author ID (ORCID Number) & \multicolumn{3}{|l}{ Makale Süreci / Article Process } \\
\hline O. Kayabaşı, 0000-0003-0129-1113 & Başvuru Tarihi / Submission Date & 07.04 .2019 \\
& Revizyon Tarihi / Revision Date & 16.09 .2019 \\
& Kabul Tarihi / Accepted Date & 24.09 .2019 \\
& Yayım Tarihi / Published Date & 20.03 .2020 \\
\hline
\end{tabular}

\section{Giriș (Introduction)}

Sac metal biçimlendirme, otomobil parçaları imalatında yaygın olarak kullanılmaktadır. Teknolojik gelişmelerin artması, oldukça karmaşık parçaların üretimine olanak sağlamıştır. Sac şekillendirme işlemi, metal levhaları, alüminyum kutulardan otomobil karoseri panellerine kadar birçok çeșitli bitmiş parçaları farklı şekillere dönüștürmek için kullanılan çeșitli ișlem süreçlerini belirtmektedir. Deformasyon mekaniğinin araștırılması ve anlaşılması için saç metal kalıp modelleme işlemi son zamanlarda önemli bir işlem haline gelmiştir. Konvansiyonel süreç tasarımı büyük ölçüde bir deneme yanılma prosedürü ile mevcut deneyime dayanmaktadır. Bu süreçte gerek zaman kaybı gerekse üretim maliyetlerini azaltmak için saç metal işleminin geliştirilmesi ve iyileştirilmesi için matematiksel modeller geliştirilmiştir. Son yıllarda sonlu elemanlar yöntemi (SEY), özellikle simülasyon deformasyon işlemlerinde artan bir önem kazanmıștır.

Sac metal șekillendirme işleminin kalitesi, malzemenin kalıp boşluğuna akmasıyla sağlanır. Bu nedenle, kırışma ve yırtılma gibi kusurları önlemek için malzeme akış hızını kontrol etmek önemlidir. Ayrıca, otomobil karoseri imalatında, esneklik nedeniyle dıș panellerin yeterli gerilmeye maruz kalması önemlidir. Genel olarak, malzeme akışı pot çemberleri tarafından kontrol edilir. Saç metal ve kalıp arasında sürtünme ile bir sınırlama kuvveti oluşturulur. Bu çalışmada, geri yaylanma, buruşma ve kalınlık azalmasını en aza indirmek için çift pot çemberi kullanılmıştır.

Saç metal prosesinde buruşma giderek artan en yaygın sorunlardan biri haline gelmiştir. Bazı kabul edilemez deformasyon biçimleri derin çekme parçaları için sac metal şekillendirmede kilit yüzey sorunlarından biridir. Bunun yanında diğer sorunlardan biride üniform kalınlık, gerilme distorsiyonu ve geri yaylanma olarak sıranalabilir. Araştırmacılar normalde ilk boş kontur, sürtünme koşulu, çekme direnci ve boş tutucu gibi işlem parametrelerinin birini veya birkaçını düzenlemeye çalıșmaktadırlar. Șekillendirme ișlemleri sırasında sac metalin kırışması kalıpta deformasyona neden olabilir. Așırı derecede ki bu deformasyon sac metal kalıbına zarar verebilir veya tahrip edebilir. Saç metal şekillendirme işlemi esnasında buruşma neticesinde zarar görmüş bir kalıp örneği Şekil l'de gösterilmektedir. Otomotiv panellerinin şekillendirilmesi için kullanılan kalıplar yüksek maliyetli ve karmaşık imalat işlemlerine sahip olduğundan, sac metal şekillendirme işlemlerinde buruşmanın tahmin edilmesi ve önlenmesi son derece önemlidir.

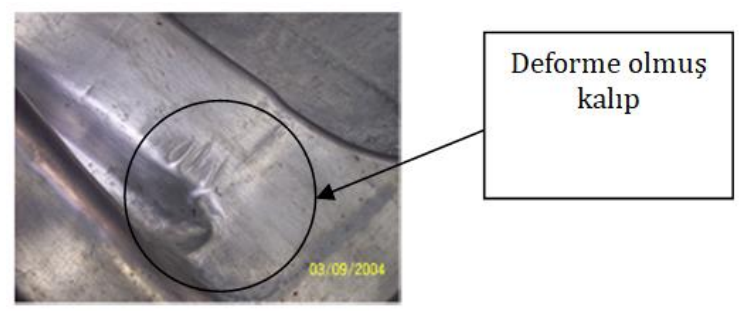

Şekil 1. Buruşma neticesi deforme olmuş kalıp (Damaged die by wrinkling.)

\section{Kaynak Araştırması (LiteratureSurvey)}

Literatürde araştırmacılar, yaylanma ve buruşma problemini azaltmak için etkili yöntemleri araştırmışlardır. Şekillendirme işlemlerinde, işlem parametrelerinin şekillendirme performansı üzerindeki etkisi çoğu zaman ilgi çekicidir. Şekillendirme işlemleri sırasında buruşma ve yaylanma etkilerini araştırmak için çeşitli analitik yöntemler geliştirilmiş ve kullanılmıştır (Choi T.H. ve Huh H., 1997), (Gasper G. vd., 2002), (Xiaoxiang S. vd., 2004), (Jansson T. Vd., 2005), (Hillmann M., 1999), (Ghouati O. vd., 1999), (Ohata T. vd., 1999). Buruşmanın başlaması analitik ve sayısal olarak araştırılmıștır (Cao J. ve Boyce M., 1997), (Cao J. vd., 1997), (Cao J. ve Wang X., 1999), (Wang X. ve Cao J., 1998).

Bu yöntemlerin çoğu, şekillenebilirlik özelliklerini doğru bir şekilde tahmin etmede sınırlamaları vardır. Son yıllarda, sayısal yöntemler, özellikle Sonlu elemanlar yöntemi (SEY), bilgisayar ortamında biçimlendirme işlemlerini simüle etmede büyük popülerlik kazanmıștır. Günümüzde SEY, şekillendirme endüstrisindeki potansiyel şekillendirme hatalarını analiz etmede standart bir araç haline gelmiştir (Choi T.H. ve Huh H., 1997), (Gasper G. vd., 2002), (Xiaoxiang S. vd., 2004), (Jansson T. Vd., 2005). 
Sac metal șekillendirme ișleminde bir diğer sorun ise geri yaylanmadır. Geri yaylanmanın en aza indirilmesi, kalıp tasarımında ana hedeflerden biridir, çünkü bu tür kusurlar sonraki montajı etkiler. Geri yaylanma hem maddi özellik hem de kalıp konfigürasyonunun bir fonksiyonudur. Uygulamada geri yaylanmayı telafi etmek için bazı yöntemler vardır. Geri yaylanmanın tahmini için akma gerilmesi ve gerilme-sertleșme üssü ve takım geometrisi gibi malzeme özelliklerine dayanarak bazı araștırmacılar matematiksel model geliștirmișlerdir (Radha Krishna Lal vd., 2018), (Wang C. vd., 1993), (Prasad Y. ve Somasundaram S., 1993). Sonlu elemanlar yöntemi kusursuz modeller ile çalışmaktadır ancak imalat sürecinde hiçbir şey mükemmel değildir. Üretim süreçlerinde öngörülemeyen tasarım parametreleri ortaya çıkar. Bu öngörülemeyen parametrelerin neden olduğu riskleri önlemek için, tasarımcılar güvenlik faktörlerini kullanır. Güvenlik faktörü yerine son yıllarda bazı tasarımcılar da olasılık tabanlı tasarım tekniklerini kullanmaya başlamıştır.

Bu çalışmanın temel amacı, saç metal parçanın şekillenebilirliğini geliştirmektir. Bu amaçla bir otomobil panelinin şekillendirilmesi sırasında olası hataları önlemek için etkili bir yaklaşımın geliştirilmesi ve kullanılması için üç yaklaşım önerilmiştir. İlk yaklaşımda, yaylanma, buruşma ve kalınlık azaltma etkilerinin azaltılmasında çift pot çemberi kullanımı araştırılmıştır. Pot çemberinin kalıp tasarımında kullanılmasının amacı, sac metalin kalıp içerisinde şekillenmeye başladığı anda buruşmasını önlemektir. Pot çemberi sayesinde belli bir kuvvetle sac metale baskı uygulanarak buruşma önlenebilir. Baskı kuvvetinin artırılması sac metalde yırtılmalara, baskı kuvvetinin azaltılması da buruşmanın artmasına sebebiyet vereceğinden buruşmayı en aza indirmek için ikinci bir pot çemberi devreye sokularak buruşmanın ortadan kaldırılması amaçlanmıştır. İkinci yaklaşımda, otomobil panelinin şekillendirilebilirliğinin daha da iyileştirilmesinde optimizasyon yönteminin kullanımı araştırılmıştır. Optimizasyon yöntemiyle, optimum şekillendirme özellikleri için, şekillendirme işlemi parametrelerinin uygun değerleri (üst kalıbın ve çekme kalıbının konumları, çekme kalıbı yarıçapı, üst kalıp yüzeyine uygulanan kuvvetler ve çift pot çemberi yüzeyleri) hesaplanmıştır. Optimum değerleri bulmada, sonlu elemanlar simülasyonu, tepki yüzeyi metodolojisi ve genetik algoritma birleştirilmiştir. Verimli ve etkili bir bağlantı sağlamak için bir bilgisayar programı yazılmıştır. Üçüncü yaklaşımda olasılık tabanlı tasarım yöntemi Monte Carlo Simülasyonu, otomatik bir tasarım aracı oluşturmak için entegre edilmiştir. Sonuçların güvenilirliği, olasılık tabanlı tasarım teknikleri kullanılarak kontrol edilmiș ve iyileștirilmiștir. Yukarıda belirtilen yaklașımların detayları aşağıdaki bölümlerde açıklanmıştır.

\section{Materyal ve Yöntem (Material and Method)}

\subsection{Sonlu Elemanlar Modeli (Finite Element Model)}

Bu çalışmada, bir otomobil yan panelinin şekillendirilme işlemi esnasında geri yaylanma, buruşma ve kalınlık azalmasını araştırmak için SEY kullanılmıştır. Çalışmamızda kullanılan araç paneli ticari olarak satılan bir araca ait olup Şekil 2a'da gösterilmektedir. Araç yan paneli 3300x2400x1mm boyutlara sahip ve alüminyum malzemeden üretilmiştir (AA5182-H0). Panelin 3 boyutlu koordinat ölçme tezgahındaki ölçüm şekli Şekil 2 a'da, panelin sonlu elemanlar modeli Şekil 2b'de gösterilmektedir.

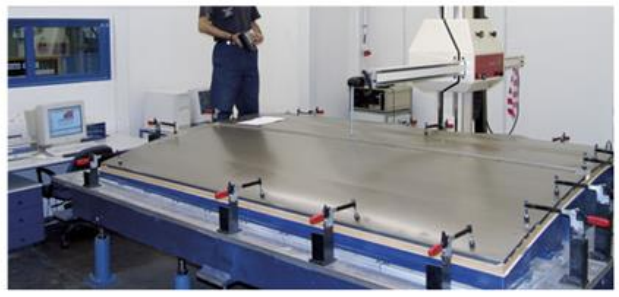

(a)

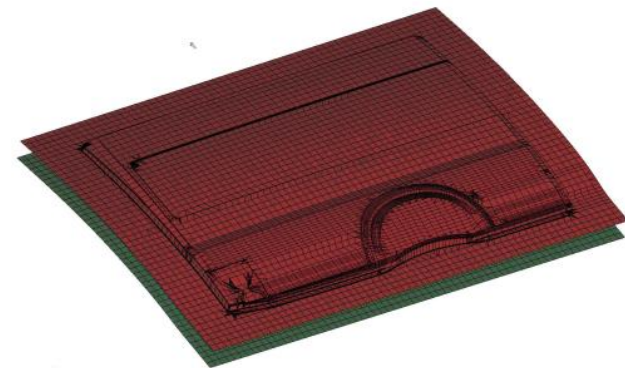

(b)

Şekil 2. a) Otomobil paneli b) Sonlu elemanlar modeli ((a) Automobile side panel (b) Finite element model)

Bu çalışmada otomobil panelinin şekillendirme işlemi, LS DYNA'da geliștirilen SEY kodu kullanılarak simüle edilmiștir (Stander N. vd., 2004). Şekillendirme simülasyonu, RAM 64 Gbyte bilgi işlem platformu ile Linux küme süper bilgisayar IBM x serisinde gerçekleştirilmiştir. Sonlu elemanlar modeli, 3 parametreli Barlat malzeme modeli boyunca yedi entegrasyon noktasına sahip Belytschko-Tsay kabuk elemanı kullanılarak oluşturulmuştur. 3 parametreli Barlat malzeme modeli 1989 yılında düzlem gerilme koşullarında modelleme için Barlat ve Lian tarafından geliştirilmiştir, Barlat modelinin matematiksel ayrıntıları referansta bulunabilir (Hallquist J. 0., 2003). 3 parametreli Barlat malzeme modelinin mekanik özellikleri Tablo 1'de gösterilmiştir. 
Tablo 1. Barlat malzeme modeli (Barlat materials model)

\begin{tabular}{|l|c|c|}
\hline \multicolumn{1}{|c|}{ PARAMETRE } & NOTASYON & DEĞER \\
\hline Yoğunluk $\left(\mathrm{g} / \mathrm{cm}^{3}\right)$ & $\rho$ & 2,7 \\
\hline Young modülü $(\mathrm{GPa})$ & $\mathrm{E}$ & 69 \\
\hline Poisson oranı & $v$ & 0,33 \\
\hline Gerinim sertleșme üsteli & $\mathrm{n}$ & 0,27 \\
\hline Mukavemet katsayısı (MPa) & $\mathrm{k}$ & 558 \\
\hline Barlat üsteli & $\mathrm{m}$ & 6 \\
\hline Lankford parametresi & $\mathrm{R}_{0}$ & 0,85 \\
\hline Lankford parameteresi & $\mathrm{R}_{45}$ & 0,77 \\
\hline Lankford parameteresi & $\mathrm{R}_{90}$ & 0,90 \\
\hline
\end{tabular}

Sonlu elemanlar analiz (SEA) sonuçları, otomobil panelinde Şekil 3'te gösterilen birçok nokta için geri besleme deneysel ölçümlerine karşı doğrulanmıștır. Deneysel ölçümler Şekil 2a'da gösterildiği gibi 3 boyutlu koordinat ölçme tezgahı ile FORD Firmasının ölçüm standartları baz alınarak gerçekleștirilmiştir. Farklı yönlerde geri yaylanma için deney ve SEA'nin karşılaştırılması (X ve Z yönleri) Tablo 2'de gösterilmektedir. Bu çalışmada ölçüm noktaları Şekil 3'te gösterildiği gibi FORD Firması kalite kontrol föyüne göre 29 noktadan seçilmiștir.

Tablo 2. X ve Z yönlerindeki geri yaylanma ölçümleri (Measurement springback X and Z direction)

\begin{tabular}{|c|c|c|c|c|}
\hline \multirow{3}{*}{ ÖLÇÜM NOKTASI } & \multicolumn{4}{|c|}{ GERI YAYLANMA (mm) } \\
\hline & \multicolumn{2}{|c|}{ DENEYSEL } & \multicolumn{2}{|c|}{ SEA } \\
\hline & $\mathbf{x}$ & $\mathbf{Z}$ & $\mathbf{x}$ & $\mathrm{Z}$ \\
\hline 1 & 0,658 & 0,850 & 0,726 & 1,003 \\
\hline 2 & 0,518 & 0,769 & 0,674 & 0,939 \\
\hline 3 & 0,523 & 0,770 & 0,672 & 0,938 \\
\hline 4 & 0,519 & 0,768 & 0,673 & 0,942 \\
\hline 5 & 0,515 & 0,772 & 0,679 & 0,945 \\
\hline 6 & 0,513 & 0,773 & 0,675 & 0,943 \\
\hline 7 & 0,518 & 0,769 & 0,674 & 0,945 \\
\hline 8 & 0,658 & 0,848 & 0,726 & 1,009 \\
\hline 9 & 0,650 & 0,844 & 0,718 & 1,010 \\
\hline 10 & 0,655 & 0,839 & 0,719 & 1,015 \\
\hline 11 & 0,645 & 0,823 & 0,726 & 0,995 \\
\hline 12 & 0,639 & 0,841 & 0,718 & 1,020 \\
\hline 13 & 0,645 & 0,852 & 0,719 & 1,022 \\
\hline 14 & 0,650 & 0,836 & 0,732 & 1,010 \\
\hline 15 & 0,646 & 0,837 & 0,733 & 1,013 \\
\hline 16 & 0,675 & 0,839 & 0,739 & 1,003 \\
\hline 17 & 0,656 & 0,835 & 0,740 & 1,006 \\
\hline 18 & 0,659 & 0,832 & 0,726 & 1,001 \\
\hline 19 & 0,640 & 0,851 & 0,726 & 0,995 \\
\hline 20 & 0,645 & 0,862 & 0,727 & 0,998 \\
\hline 21 & 0,642 & 0,846 & 0,730 & 1,012 \\
\hline 22 & 0,629 & 0,842 & 0,714 & 1,015 \\
\hline 23 & 0,656 & 0,850 & 0,713 & 1,019 \\
\hline 24 & 0,651 & 0,829 & 0,712 & 1,011 \\
\hline 25 & 0,659 & 0,838 & 0,710 & 1,015 \\
\hline 26 & 0,618 & 0,889 & 0,734 & 1,056 \\
\hline 27 & 0,617 & 0,889 & 0,736 & 1,061 \\
\hline 28 & 0,616 & 0,888 & 0,740 & 1,062 \\
\hline 29 & 0,619 & 0,887 & 0,745 & 1,049 \\
\hline
\end{tabular}




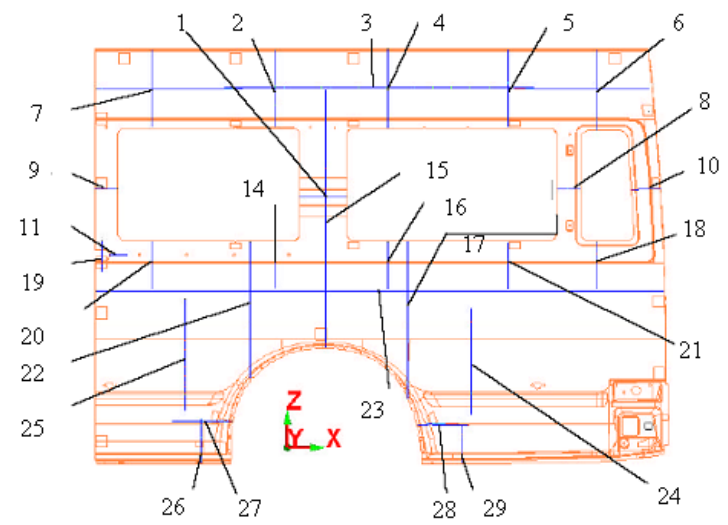

Şekil 3. Geri yaylanma ölçüm noktaları (Measurement springback point)

Tablo 2'den, sonlu elemanlar modelinin sonuçlarının deneysel ölçümlerle oldukça iyi korele olduğu görülmektedir. Bu nedenle, şekillendirme işlemlerinde parametrik çalışmalar için kullanılabilir. Sonlu elemanlar analizi (SEA) simülasyonları kullanılarak, geri yaylanma sonuçlarında çift pot çemberi kullanımının etkisi araştııılmıştır. SEA sonuçları, çift pot çemberinin kullanmanın ince panelin geri yaylanmasını önemli ölçüde azalttığını göstermektedir. Tek pot çemberi kullanarak (geleneksel şekilde) ve çift pot çemberi kullanarak (önerilen şekilde) performans oluşturma Şekil 4-5'te gösterilmektedir. Şekil 4a ve 5a, tek pot çemberi kullanma durumunu gösterirken, Şekil $4 \mathrm{~b}$ ve $5 \mathrm{~b}$, çift pot çemberi kullanma durumunu göstermekedir. Şekil $4 \mathrm{~b}$ ve $5 \mathrm{~b}$, çift pot çemberi kullanmanın șekillendirme kusurlarını, burușma ve kalınlık azaltma gibi sorunları önemli ölçüde azalttığını göstermektedir. Buruşmaya maruz kalan alanlar da önemli ölçüde azalmıştır. Kalınlık azaltma \% 50'den \% 4'e düşmüştür. Bu nedenle, aşağıdaki bölümlerde panelin şekillendirilebilirliğinde daha fazla iyileştirme için temel bağlayıcı model olarak çift pot çember kullanımlı sonlu elemanlar modeli benimsenmiștir.

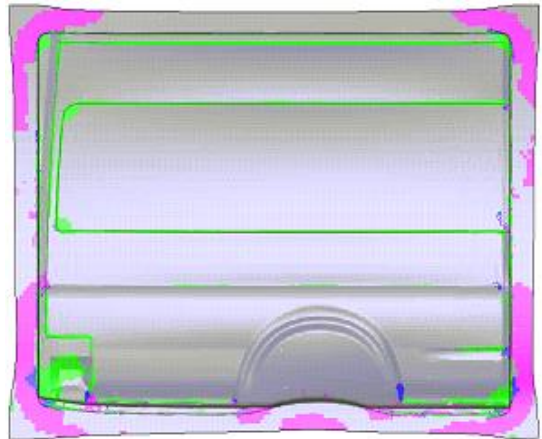

(a)

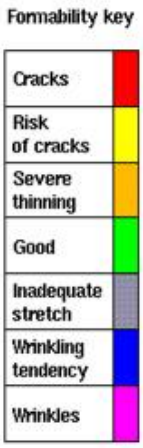

b) cift pot cemberi (Formability of

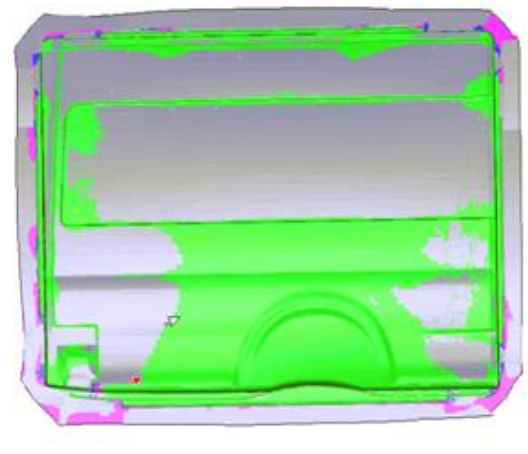

(b)

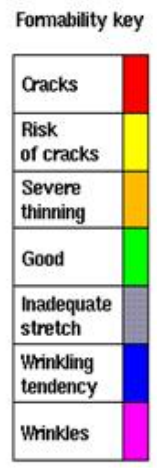

Sekil 4. Panelin șekillenebilirliği a) tek pot çemberi b) çift pot çemberi (Formability of the side panel: a) using one binder and b) using double binder.)

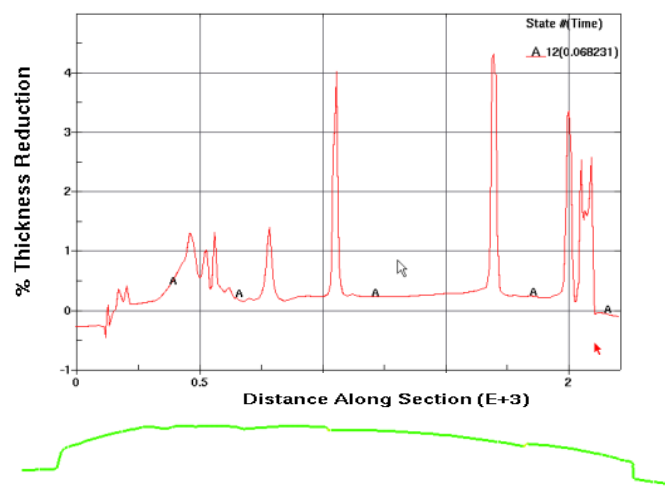

(a)

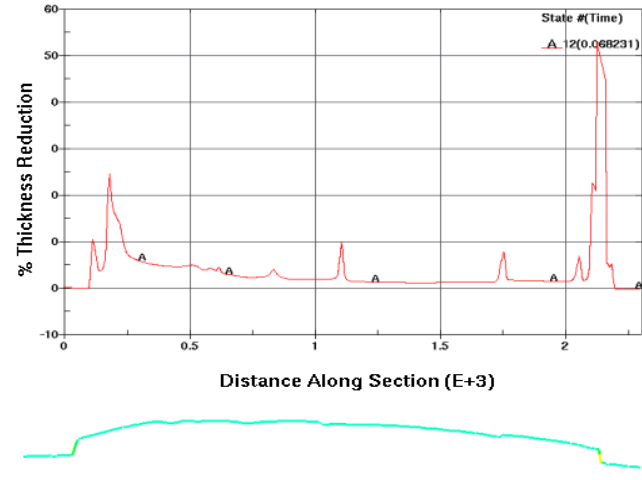

(b)

Şekil 5. Kalınlık azalması dağılımı a) tek pot çemberi b) çift pot çemberi (Distribution of thickness reduction on the cross section of the side panel: a) using one binder and b) using double binder.) 


\subsection{Süreç Parametrelerinin Ayarlanması İçin Optimizasyon Metodolojisi (Optimization Methodology For Adjusting Process Parameters)}

panellerinin şekillendirilmesinde yaylanma, kalınlık azaltması ve buruşma asgari olması istenir. Literatürde süzme çubuğu geometrisi, süzme çubuğu konumu ve baskı kuvvetinin çoğunlukla geri yaylanma, kalınlık azaltması ve otomobil panellerinin buruşma sonuçlarını etkilediği düşünülmektedir. Geri yaylanmayı etkileyen önemli parametrelere, kalınlık azalmasına ve buruşmaya karar verildikten sonra, bir sonraki işlem bu parametreleri dikkatlice istenen sonuçlara götürecek şekilde ayarlamaktır. Bu çalışmada üst kalıbın ve süzme çubuğunun pozisyonu, süzme çubuğu yarıçapı üst kalıp yüzeyine uygulanan kuvvetler ve çift pot çemberi yüzyleri etkin işlem parametreleri olarak kabul edilmiştir. Bu parametreler Şekil 6'da gösterilmektedir. Şekil 6'da, X(1) üst kalıbın (yani pistonun) panelin merkezinden uzaklığıdır, X(2) süzme çubuğunun panelin merkezinden uzaklığl, R(2) süzme çubuğunun yarıçapı, F(1) üst kalıba uygulanan kuvvet, F(2) pot çemberi II baskı kuvveti, F(3) pot çemberi I'e uygulanan baskı kuvvetidir.

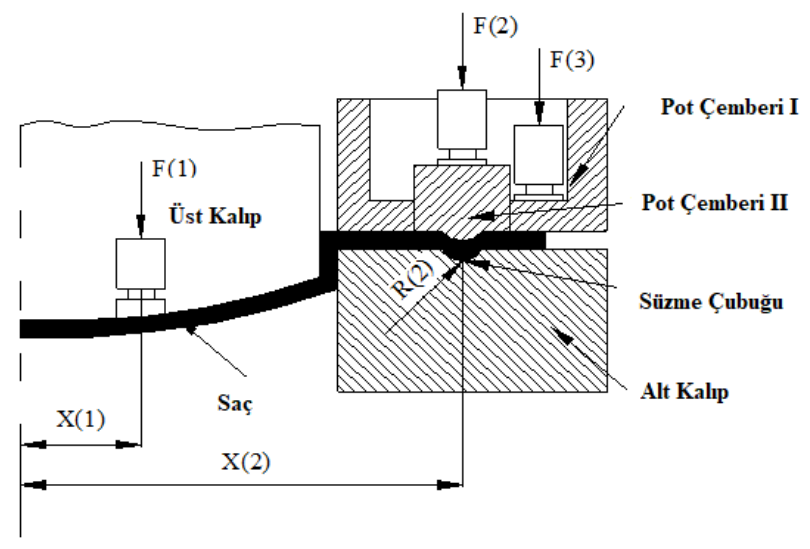

Şekil 6. Şekillendirme işlemi parametreleri (Process parameters of formability)

Proses parametrelerinin deneme ve yanılma ile belirlenmesi (ayarlanması) birçok hesaplama açısından maliyetlidir. $\mathrm{Bu}$ amaçla daha etkili bir yaklaşım ve uygun bir optimizasyon metodolojisinin benimsenmesi amaçlanmaktadır. Optimizasyon metodolojisinde, istenen şekillendirme kriteri, işlem parametreleri olarak amaç (lar) ve sinırlama fonksiyonu (fonksiyonları) olarak ifade edilir. Bu fonksiyonlar daha sonra sayısal bir optimizasyon metodu ile optimum parametre değerlerini bulmak için çözülür.

Panel oluşumu durumunda, optimizasyon problemi aşağıdaki gibi tanımlanır:

İslem parametrelerini bul:

$\mathrm{X}(1), \mathrm{X}(2), \mathrm{R}(2), \mathrm{F}(1), \mathrm{F}(2), \mathrm{F}(3)$

Amaç fonksiyonunu minimize et:

Geri yaylanma/Buruşma/Kalınlık azalması

Sinır șartları:

Geri yaylanma $\leq$ Geri yaylanma_limiti

Buruşma $\leq$ Buruşma_limiti

Kalınlık azalması $\leq$ Kalınlık azalması_limiti

Parametre aralıkları

$$
\begin{aligned}
& 1300 \mathrm{~mm} \leq \mathrm{X}(1) \leq 1500 \mathrm{~mm} \\
& 1675 \mathrm{~mm} \leq \mathrm{X}(2) \leq 1695 \mathrm{~mm} \\
& 8 \mathrm{~mm} \leq \mathrm{R}(2) \leq 15 \mathrm{~mm} \\
& 600 \text { ton } \leq \mathrm{F}(1) \leq 900 \text { ton } \\
& 200 \text { ton } \leq \mathrm{F}(2) \leq 400 \text { ton } \\
& 250 \text { ton } \leq \mathrm{F}(3) \leq 450 \text { ton }
\end{aligned}
$$

Otomotiv endüstrisinde önerilen değerlere dayanarak X(1), X(2), R (2), F (1), F (2) ve F (3) aralıkları seçilmiştir (Personal Communication, FORD OTOSAN TURKEY, 2005). Geri yaylanma_limiti, buruşma_limiti ve kalınlık azalması_limiti, optimizasyondan sonra sırasıyla geri yaylanma, buruşma ve kalınlık azaltma değerlerinde karşılanacak üst sınır değerlerini temsil eder. Bir sonraki bölümde Tablo 3 'te verilen değerlerin ortalaması olarak alınmıștır. Amaç ve kısıtlama fonksiyonları, optimizasyon işleminin başlamasından önce açıkça bilinmemektedir. Tablo 3 'teki verileri kullanarak Yanıt Yüzeyi Metodolojisi (YYM) kullanılarak SEA sonuçlarından elde edilmiştir. YYM, aşağıdaki bölümde ayrıntılı olarak açıklanmaktadır. Optimizasyon problemini etkili bir şekilde çözmek için Genetik Algoritma (GA) programı geliștirilmiştir. Global bir optimum bulmak için geri yaylanma, buruşma ve kalınlık azaltma gibi YYM bazlı analitik modeller ile entegre edilmiştir. 
GA uygulamasında, popülasyon büyüklüğü 50, çaprazlama oranı 1.0, mutasyon oranı 0.1, her bir değişken için bit sayısı 16 ve kuşak sayısı 500 olarak kullanılmıştır. Bu parametreler birkaç denemeden sonra en iyi performans için optimize edilmiștir. Bu çalışmada geliştirilen GA, objektif değere ve kısıtlama ihlali seviyesine dayalı kromozomları seçmektedir. Kromozomların uygunluk değerleri asgari objektif değere ve geçit evresindeki en az olanaksız kümelere doğru eğilim gösterecektir. Literatürdeki GA'ların çoğu, kısıtlı optimizasyon problemini, çözümden önce ceza fonksiyonlarıyla kısıtlanmamış bir optimizasyon problemine dönüştürmüștür. Bu, kullanıcı deneyimi gerektiren, soruna bağlı ceza katsayılarının uygun bir şekilde seçilmesinin zorluğunu getirmektedir. Bu çalışmada geliştirilen programda, herhangi bir probleme bağımlı katsayısına ihtiyaç duyulmadığından bu zorluk tamamen önlenmiștir.

\subsection{Geri Yaylanma, Buruşma ve Kalınlık Azalması için Yanıt Yüzey Modeli (YYM) (Response Surface Model (RSM) for Springback, Wrinkling and Thickness Reduction)}

Optimizasyon probleminin çözümü Denklemler 1-11'de verilmiştir, hesaplamalı olarak yüksek maliyetli SEA'lardan gelen amaç ve kısıtlama fonksiyonları birçok kez değerlendirilmiştir. Bu, çözüm sürecini verimsiz hale getirebilir. Daha etkili bir çözüm stratejisi, çözüm sürecinden önce YYM kullanarak amaç ve kısıtlama işlevlerini karşılık gelen daha basit analitik işlevlerle değiştirmektir. YYM, denemenin istatistiksel tasarımına ve en küçük kare hata uydurmalarına dayanan bir model oluşturma tekniği olarak tanımlanır (Myers R. H. ve Montgomery D. C., 1995). YYM, aşağıdaki gibi mevcut veriler için bir polinom işlevi yaratır:

$$
\mathrm{f}=\mathrm{a}_{0}+\sum_{\mathrm{i}=1}^{\mathrm{n}} \mathrm{a}_{\mathrm{i}} \mathrm{x}_{\mathrm{i}}+\sum_{\mathrm{i}=1 \mathrm{j}=1}^{\mathrm{n}} \sum_{\mathrm{ij}}^{\mathrm{n}} \mathrm{a}_{\mathrm{i}} \mathrm{x}_{\mathrm{j}}+\ldots . .
$$

$\mathrm{A}_{0}, \mathrm{a}_{\mathrm{i}}$ ve $\mathrm{a}_{\mathrm{ij}}$ ayarlama katsayıları ve $\mathrm{n}$ parametre sayısıdır (yani proses parametreleri). YYM tarafından üretilen polinom modelleri genellikle literatürde Yanıt Yüzeyi (YY) modelleri olarak ele anılır. YY modelleri oluşturmak için bu çalışmada bir bilgisayar programı yazılmıştır. Yeterli veri varsa, programın 10. dereceye kadar YY polinomları oluşturma yeteneği vardır. Modellerdeki tüm çapraz terimler dikkate alınabilir. YY modelleri ayrıca parametrelerin tersi yönünden de üretilebilir. Şayet istenirse, YY modelinde (yani ters) olarak değiştirilebilir. YY modellerinin oluşturulmasında, D-optimal deneysel tasarım yöntemine dayanan SEA sonuçları kullanılmıştır. İstatistiksel olarak üç seviyeli tam faktör deneysel tasarım D-optimallik için temel olarak kullanılmıştır. Kuadratik bir yanıt yüzey modeli oluşturmak için $(n+1) /(n+2) / 2$ şeklindedir. Sonuçta n, tasarım parametrelerinin sayısıdır. Literatürde modelin tahmin doğruluğunun iyileştirilmesi için gerekenden \% 50 daha fazla nokta önerilmektedir. 6 tasarım parametresi için, bu çalışmada Tablo 3 'te gösterilen 40 SEA gerçekleştirilmiştir. Tablo 3 'te işlem parametrelerinin oluşturulması, D-optimal deneysel tasarım yöntemi kullanılarak seçilmiştir. Geri yaylanma, buruşma ve kalınlık azalması için optimizasyon işleminin hesaplama maliyetini düşürmek için YYM kullanılarak en önemli proses parametreleri (X (1) mm, X (2) mm, R (2) mm F (1) ton F (2) ton F(3) ton) cinsinden üretilmiştir. $\mathrm{Bu}$ çalışmadaki optimizasyon metodolojisi diğer sac metal parçaları geliştirmek için de kullanılabileceğini göstermektedir.

Tablo 3. Parametrelerin kombinasyonu (Combination of parameters)

\begin{tabular}{|c|c|c|c|c|c|c|c|c|c|}
\hline ANALİZ & $\begin{array}{l}\mathrm{X}(1) \\
(\mathrm{mm})\end{array}$ & $\begin{array}{c}\mathrm{X}(2) \\
(\mathrm{mm})\end{array}$ & $\begin{array}{c}\mathbf{R}(2) \\
(\mathbf{m m})\end{array}$ & $\begin{array}{l}\mathrm{F}(1) \\
\text { (ton) }\end{array}$ & $\begin{array}{l}F(2) \\
\text { (ton) }\end{array}$ & $\begin{array}{l}F(3) \\
\text { (ton) }\end{array}$ & $\begin{array}{c}\text { GERİ YAYLANMA } \\
(\mathrm{mm})\end{array}$ & $\begin{array}{c}\text { BURUŞMA } \\
(\mathrm{mm})\end{array}$ & $\begin{array}{c}\text { KALINLIK } \\
\text { AZALMASI (\%) }\end{array}$ \\
\hline 1 & 1300 & 1675 & 8 & 900 & 200 & 250 & 0.528 & 2.28 & 5 \\
\hline 2 & 1300 & 1675 & 8 & 600 & 400 & 250 & 0.643 & 2.43 & 5 \\
\hline 3 & 1500 & 1675 & 15 & 600 & 400 & 450 & 0.617 & 2.36 & 4 \\
\hline 4 & 1300 & 1695 & 15 & 600 & 400 & 350 & 0.619 & 2.37 & 4 \\
\hline 5 & 1500 & 1695 & 8 & 900 & 400 & 450 & 0.516 & 2.21 & 6 \\
\hline 6 & 1300 & 1695 & 8 & 600 & 200 & 250 & 0.652 & 2.52 & 6 \\
\hline 7 & 1500 & 1675 & 12 & 900 & 200 & 450 & 0.508 & 2.20 & 3 \\
\hline 8 & 1300 & 1695 & 8 & 600 & 400 & 450 & 0.610 & 2.35 & 4 \\
\hline 9 & 1300 & 1695 & 8 & 900 & 200 & 450 & 0.598 & 2.33 & 4 \\
\hline 10 & 1300 & 1675 & 8 & 900 & 400 & 450 & 0.568 & 2.29 & 4 \\
\hline 11 & 1400 & 1675 & 8 & 600 & 200 & 350 & 0.602 & 2.35 & 4 \\
\hline 12 & 1400 & 1675 & 15 & 750 & 200 & 450 & 0.548 & 2.29 & 3 \\
\hline 13 & 1500 & 1695 & 8 & 900 & 200 & 250 & 0.413 & 2.15 & 4 \\
\hline 14 & 1300 & 1695 & 15 & 900 & 400 & 450 & 0.315 & 2.10 & 3 \\
\hline 15 & 1500 & 1685 & 15 & 900 & 300 & 350 & 0.317 & 2.11 & 3 \\
\hline 16 & 1300 & 1695 & 15 & 900 & 200 & 250 & 0.420 & 2.17 & 2 \\
\hline 17 & 1500 & 1695 & 8 & 600 & 300 & 350 & 0.499 & 2.25 & 5 \\
\hline 18 & 1500 & 1695 & 15 & 600 & 200 & 450 & 0.481 & 2.23 & 3 \\
\hline 19 & 1500 & 1685 & 8 & 600 & 400 & 250 & 0.492 & 2.24 & 4 \\
\hline 20 & 1500 & 1675 & 15 & 600 & 200 & 250 & 0.473 & 2.20 & 3 \\
\hline 21 & 1500 & 1675 & 8 & 900 & 300 & 250 & 0.412 & 2.19 & 5 \\
\hline 22 & 1300 & 1675 & 12 & 600 & 200 & 450 & 0.419 & 2.21 & 4 \\
\hline 23 & 1400 & 1685 & 12 & 600 & 300 & 250 & 0.400 & 2.18 & 4 \\
\hline 24 & 1400 & 1675 & 15 & 900 & 400 & 250 & 0.390 & 2.16 & 3 \\
\hline 25 & 1500 & 1675 & 12 & 750 & 400 & 350 & 0.398 & 2.17 & 4 \\
\hline 26 & 1500 & 1695 & 15 & 750 & 400 & 250 & 0.383 & 2.14 & 2 \\
\hline 27 & 1500 & 1685 & 8 & 750 & 200 & 450 & 0.403 & 2.18 & 4 \\
\hline 28 & 1300 & 1695 & 8 & 900 & 400 & 250 & 0.406 & 2.15 & 5 \\
\hline
\end{tabular}


Tablo 3. Devamı (Continuned)

\begin{tabular}{|c|c|c|c|c|c|c|c|c|c|}
\hline ANALIZZ & $\begin{array}{l}X(1) \\
(\mathrm{mm})\end{array}$ & $\begin{array}{l}X(2) \\
(\mathrm{mm})\end{array}$ & $\begin{array}{c}\mathbf{R}(2) \\
(\mathrm{mm})\end{array}$ & $\begin{array}{l}F(1) \\
\text { (ton) }\end{array}$ & $\begin{array}{l}F(2) \\
\text { (ton) }\end{array}$ & $\begin{array}{l}F(3) \\
\text { (ton) }\end{array}$ & $\begin{array}{l}\text { GERI YAYLANMA } \\
(\mathrm{mm})\end{array}$ & $\begin{array}{c}\text { BURUŞMA } \\
\text { (mm) }\end{array}$ & $\begin{array}{c}\text { KALINLIK } \\
\text { AZALMASI (\%) }\end{array}$ \\
\hline 29 & 1350 & 1695 & 13 & 900 & 400 & 450 & 0.383 & 2.09 & 3 \\
\hline 30 & 1400 & 1695 & 13 & 900 & 400 & 450 & 0.376 & 2.05 & 3 \\
\hline 31 & 1450 & 1695 & 13 & 900 & 400 & 450 & 0.375 & 2.05 & 3 \\
\hline 32 & 1500 & 1695 & 13 & 900 & 400 & 450 & 0.371 & 2.05 & 3 \\
\hline 33 & 1300 & 1675 & 15 & 900 & 400 & 450 & 0.378 & 2.05 & 2 \\
\hline 34 & 1350 & 1675 & 15 & 900 & 400 & 450 & 0.377 & 2.04 & 2 \\
\hline 35 & 1400 & 1675 & 15 & 900 & 400 & 450 & 0.375 & 2.05 & 2 \\
\hline 36 & 1400 & 1695 & 10 & 900 & 400 & 450 & 0.392 & 2.06 & 2 \\
\hline 37 & 1450 & 1695 & 10 & 900 & 400 & 450 & 0.390 & 2.02 & 4 \\
\hline 38 & 1500 & 1695 & 10 & 900 & 400 & 450 & 0.387 & 2.08 & 4 \\
\hline 39 & 1300 & 1675 & 11 & 900 & 400 & 450 & 0.381 & 2.06 & 4 \\
\hline 40 & 1350 & 1675 & 11 & 900 & 400 & 450 & 0.380 & 2.05 & 5 \\
\hline
\end{tabular}

\section{4. İşlem Parametreleri Oluşturma İçin Optimizasyon Sonuçları (Optimization Results for Generating Process Parameters)}

1-11 Denklemlerle temsil edilen optimizasyon problemi birkaç durum için çözülmüştür. Her durumda, belirtilen şekillendirme kriterlerini en aza indirmek için en uygun işlem parametreleri aranmıștır. Bu aşamada GA optimizasyon seçilerek $X(1), X(2), R(2), F(1), F(2)$ ve $F(3)$ değerleri belirlenerek geri yaylanma, buruşma ve kalınlık azalması değerleri hesaplanmıştır. Bu çalışmada 4 durum için değerlendirme çalışması yapılmıştır.

Örneğin, 1. durumda, otomobil paneli için geri yaylanma asgariye indirmiștir. 2. Durumda buruşma minimize edilmiştir. 3. durumda, kalınlık azalması en aza indirilmiștir. 4. durumda, yaylanma, buruşma ve kalınlık azalması aynı anda en aza indirilmiştir. Her durumda, kısıtlama fonksiyonları 6-11 Denklemlerinde verilenlerle aynıdır.

Durum I'de optimizasyon hedefi, otomobil panelindeki geri yaylanmayı en aza indirmektir. Bu amaca ulaşmak için bulunan optimum biçimlendirme parametresi değerleri Tablo 4'te gösterilmektedir. Durum II'de optimizasyonun amacl, otomobil panelinde sadece buruşmayı en aza indirmektir. Bu amaca ulaşmak için bulunan optimum biçimlendirme parametresi değerleri Tablo 5'de gösterilmektedir. Durum III'de optimizasyon amacı, otomobil panelinde sadece kalınlık azalmasını en aza indirmektir. Bu amaca ulaşmak için bulunan optimum biçimlendirme parametresi değerleri Tablo 6'da gösterilmektedir. Durum IV'te, yaylanma, buruşma ve aynı zamanda kalınlık azalmasını en aza indirmek için çok amaçlı optimizasyon uygulanır. Bu amaca ulaşmak için bulunan optimum biçimlendirme parametresi değerleri Tablo 7'de gösterilmektedir.

Tablo 4-7'den itibaren, bu çalışmada kullanılan optimizasyon metodolojisinin geri yaylanma, buruşma ve kalınlık azalması için istenen sonuçlara yol açtığı görülmektedir. GA'dan optimizasyon sonuçları SEA'lerinden gelenlerle de iyi koreledir. Optimizasyon sonuçları yaylanma, burușma ve tek amaç ișlevi durumunda çok amaçlı ișlev durumunda kalınlığın azaltılması için daha iyidir. Tablolardan, X(2), R(2) ve F(1) 'in ișlem parametrelerinin oluşturulmasının, optimizasyon kriterleri değiştiğinde fazla değişmediği de görülmektedir. $F(3)$ çok az değişmekte bununla birlikte, $X(1)$ ve $F(2)$ belirtilen oluşturma kriterlerine göre değişmektedir. Okuyucu için bir hatırlatıcı olarak, optimizasyon ișleminde daha sofistike YY modelleri (kübik veya dördüncü dereceden poynomial'ler gibi) inşa edilerek ve kullanarak GA tarafından optimum hale getirilebilir. Bununla birlikte, bu gelişme ekstra SEA'lerin maliyeti ile birlikte gelir.

Tablo 4. Geri yaylanmada şekillendirme işlem parametresi (Forming process parameter in springback)

\begin{tabular}{|c|c|c|c|c|c|c|c|c|c|}
\hline & \multirow{2}{*}{$\begin{array}{l}\text { GERI YAYLANMA } \\
\text { (mm) }\end{array}$} & \multirow{2}{*}{$\begin{array}{c}\text { BURUSSMA } \\
\text { (mm) }\end{array}$} & \multirow{2}{*}{$\begin{array}{c}\text { KALINLIK } \\
\text { AZALMA } \\
\text { (\%) }\end{array}$} & \multicolumn{6}{|c|}{ OPTIMUM ŞEKILLENDIRME PROSES PARAMETRELERI } \\
\hline & & & & $\begin{array}{l}\mathrm{X}(1) \\
(\mathrm{mm})\end{array}$ & $\begin{array}{l}\mathrm{X}(2) \\
(\mathrm{mm})\end{array}$ & $\begin{array}{l}\mathrm{R}(2) \\
(\mathrm{mm})\end{array}$ & $\begin{array}{l}\text { F(1) } \\
\text { (N) }\end{array}$ & $\begin{array}{l}F(2) \\
\text { (N) }\end{array}$ & $\begin{array}{l}F(3) \\
\text { (N) }\end{array}$ \\
\hline GA & 0.1062 & 1.9001 & 2.3665 & 1377.2 & 1694.1 & 14.8 & 896 & 340 & 251 \\
\hline
\end{tabular}

Tablo 5. Buruşmada şekillendirme işlem parametresi (Forming process parameter in wrinkling)

\begin{tabular}{|c|c|c|c|c|c|c|c|c|c|}
\hline & \multirow{2}{*}{$\begin{array}{c}\text { GERI } \\
\text { YAYLANMA } \\
\text { (mm) }\end{array}$} & \multirow{2}{*}{$\begin{array}{c}\text { BURUŞMA } \\
\text { (mm) }\end{array}$} & \multirow{2}{*}{$\begin{array}{c}\text { KALINLIK } \\
\text { AZALMA } \\
\text { (\%) }\end{array}$} & \multicolumn{6}{|c|}{ OPTIMUM ŞEKILLENDİRME PROSES PARAMETRELERI } \\
\hline & & & & $\begin{array}{c}\mathbf{X}(\mathbf{1}) \\
(\mathrm{mm})\end{array}$ & $\begin{array}{c}\mathrm{X}(2) \\
(\mathrm{mm})\end{array}$ & $\begin{array}{c}\mathbf{R}(2) \\
(\mathrm{mm})\end{array}$ & $\begin{array}{l}\text { F(1) } \\
\text { (N) }\end{array}$ & $\begin{array}{l}\text { F(2) } \\
\text { (N) }\end{array}$ & $\begin{array}{l}\mathbf{F}(3) \\
\text { (N) }\end{array}$ \\
\hline GA & 0.1103 & 1.8996 & 2.1272 & 1395.5 & 1693.4 & 15 & 899.7 & 313.2 & 254.7 \\
\hline
\end{tabular}


Tablo 6. Kalınlık azalmada şekillendirme ișlem parametresi (Forming process parameter in thickness reduction)

\begin{tabular}{|c|c|c|c|c|c|c|c|c|c|}
\hline & \multirow{2}{*}{$\begin{array}{c}\text { GERİ } \\
\text { YAYLANMA } \\
\text { (mm) }\end{array}$} & \multirow{2}{*}{$\begin{array}{c}\text { BURUŞMA } \\
\text { (mm) }\end{array}$} & \multirow{2}{*}{$\begin{array}{c}\text { KALINLIK } \\
\text { AZALMA } \\
\text { (\%) }\end{array}$} & \multicolumn{6}{|c|}{ OPTIMUM ŞEKILLENDİRME PROSES PARAMETRELERİ } \\
\hline & & & & $\begin{array}{c}X(1) \\
(\mathrm{mm})\end{array}$ & $\begin{array}{c}X(2) \\
(\mathrm{mm})\end{array}$ & $\begin{array}{c}\mathrm{R}(2) \\
(\mathrm{mm})\end{array}$ & $\begin{array}{c}F(1) \\
(N)\end{array}$ & $\begin{array}{c}F(2) \\
(N)\end{array}$ & $\begin{array}{l}F(3) \\
(N)\end{array}$ \\
\hline GA & 0.3376 & 2.0615 & 1.3817 & 1478.9 & 1694.5 & 15 & 898.4 & 205.7 & 260.6 \\
\hline
\end{tabular}

Tablo 7. Üç durumda şekillendirme işlem parametresi (Forming process parameter in three cases)

\begin{tabular}{|c|c|c|c|c|c|c|c|c|c|}
\hline & \multirow{2}{*}{$\begin{array}{l}\text { GERI YAYLANMA } \\
\text { (mm) }\end{array}$} & \multirow{2}{*}{$\begin{array}{l}\text { BURUŞMA } \\
\text { (mm) }\end{array}$} & \multirow{2}{*}{$\begin{array}{c}\text { KALINLIK } \\
\text { AZALMA } \\
\text { (\%) }\end{array}$} & \multicolumn{6}{|c|}{ OPTIMUM ŞEKILLENDIRME PROSES PARAMETRELERİ } \\
\hline & & & & $\begin{array}{c}\mathrm{X}(1) \\
(\mathrm{mm})\end{array}$ & $\begin{array}{c}X(2) \\
(\mathrm{mm})\end{array}$ & $\begin{array}{l}\mathbf{R}(2) \\
(\mathbf{m m})\end{array}$ & $\begin{array}{l}F(1) \\
(\mathrm{N})\end{array}$ & $\begin{array}{l}F(2) \\
(N)\end{array}$ & $\begin{array}{l}F(3) \\
(N)\end{array}$ \\
\hline GA & 0.3042 & 2.0325 & 1.3317 & 1463.9 & 1694.8 & 14.9 & 894.1 & 209.9 & 250.9 \\
\hline
\end{tabular}

\subsection{Olasılık Tabanlı Metot ve Monte Carlo Simülasyonu (Probability Based Method and Monte Carlo Simulation)}

Monte Carlo metodu, araştırılan değeri belirlemek için birçok rastgele denemenin oluşturulması esasına dayanmaktadır. Model girdilerindeki değişkenleri model çıktısına yaymak için spesifik olarak kullanımına örnektir. Simülasyon, girdileri tanımlayarak belirsizlikleri açıç̧a temsil etme sürecine dayanmaktadır.

Sac metal kalıp sisteminin olasılıksal tepkisi, aşağıdaki gibi modellenmiştir.

$$
\mathrm{Z}(\mathrm{X})=\mathrm{Z}\left(\mathrm{X}_{1}, \mathrm{X}_{2}, \mathrm{X}_{3}, \ldots, \mathrm{X}_{\mathrm{n}}\right)
$$

$\mathrm{Z}(\mathrm{X})$, sistemin tepkisini tanımlayan rastgele bir değişkendir (örneğin, bir düğümdeki veya elemandaki yaylanma, buruşma ve kalınlık azalması), Xi $(i=1, n)$, model giriș değişkenlerini tanımlayan rastgele değişkenlerdir. Bu çalışmada Z sonlu elemanlar modelinden elde edilmiştir. Olasılıklı cevap için Monte Carlo örnekleme teknikleri kullanılmıştır. Monte Carlo yöntemi, bir bilgisayarda istatistiksel örnekleme deneyleri yaparak çeşitli matematiksel sorunlara yaklaşık çözümler sunmaktadır.

Olasılık tabanlı optimizasyon işleminde, tasarım parametrelerinin olasılık dağılımları hesaplanmaktadır. Olasılık dağılım sonuçları, tasarımın güvenilirlik değişikliğini göstermektedir. Tasarımcl, müşteri isteklerine göre güvenilirlik değerlerini kullanır. Bu işlem, minimum maliyetle maksimum güvenlik ve kaliteye yol açar.

Olasılık tabanlı bir analizde, başarısızlık olasılığı, yapının olasılıksal tepkisi ile malzemenin olasılıksal mukavemeti karşslaştırılarak rastgele değişkenlerin bir işlevi olan bir performans işlevi formüle edilerek belirlenebilir (Demir, İ., vd., 2008).

Arıza riski, türün performans fonksiyonuna göre hesaplanmıştır.

$g(X)=R(X)-S(X)$

$\mathrm{R}(\mathrm{X})$, bileşenin direncini açıklayan rastgele bir işlev olduğunda, $\mathrm{S}(\mathrm{X})$ yapının tepkisidir (ör. Yaylanma, buruşma ve kalınlık azaltma), ayrıca rastgele bir değişkendir ve X, rastgele değişkenlerin vektörü; $\mathrm{g}$ (X) bir başarısızlık olayını temsil eder. Başarısızlık olasılığı Denklem 15'teki gibi tanımlanmıştır.

$\mathrm{pf}=\mathrm{P}(\mathrm{g}(\mathrm{X})-0)$

Sac levha kalıbı için performans fonksiyonları formüle edilip üç performans işlevi incelenmiștir.

$\mathrm{g}_{1}=\mathrm{R}_{\text {Geri yaylanma limiti- }} \mathrm{S}_{\text {Hesaplanan geri yaylanma }}$

$\mathrm{g}_{2}=\mathrm{R}_{\text {Kalınlık azalma limiti- }} \mathrm{S}_{\text {Hesaplanan kalınlık azalması }}$

$\mathrm{g}_{3}=\mathrm{R}_{\text {Buruşma limiti- }} \mathrm{S}_{\text {Hesaplanan buruşma }}$

$\mathrm{S}(\mathrm{X})$, üç boyutlu sonlu elemanlar modelinden belirlenen hesaplanmış yanıt ölçüsüdür. Olasılıklı tepki ve başarısızlık olasılığı hem ilk hem de deterministik olarak optimize edilmiş kalıp tasarımı için ölçülmüştür. Rastgele değişken istatistikleri, yazılı programdaki rastgele değişken tanımı penceresinde tanımlanır. Model giriş değişkenlerinin rastgele değişken tanımları literatürden ve gerçek deneysel test verilerinden belirlenmiştir. 3 
parametreli Barlat malzeme modelinin mekanik özellikleri Tablo 8'de gösterilmektedir. Panelin geri yaylanması, LS-DYNA özelliği kullanılarak simüle edilmiștir. Model giriș değișkenlerinin rastgele değișken tanımları, gerçek deneysel test verilerinden belirlenmiștir. Elde edilen veriler Tablo 9'da gösterilmektedir.

Tablo 8. Barlat malzeme modeli (Barlat material properties)

\begin{tabular}{|c|c|c|c|c|c|}
\hline PARAMETRE & NOTASYON & ORTALAMA & S.D & $\begin{array}{c}\text { DEĞİŞIM } \\
\text { KATSAYISI (\%) }\end{array}$ & DAĞILIM TİPI \\
\hline Yoğunluk (g/cm³) & $\rho$ & 2.7 & 0.31 & 11.3 & Lognormal \\
\hline Young Modülü (GPa) & E & 69 & 6.90 & 10 & Lognormal \\
\hline Poisson Oranı & $v$ & 0.33 & 0.028 & 8.2 & Lognormal \\
\hline Gerinim-Sertleşme Üsteli & $\mathrm{n}$ & 0.27 & 0.033 & 12 & Lognormal \\
\hline Dayanım Katsayısı (MPa) & $\mathrm{k}$ & 558 & 60.265 & 10.8 & Lognormal \\
\hline Barlat Üsteli & $\mathrm{m}$ & 6 & 0.642 & 10.7 & Lognormal \\
\hline Lankford parameter in $0^{\circ}$ & $\mathrm{R}_{0}$ & 0.85 & 0.076 & 9 & Normal \\
\hline Lankford parameter in $45^{\circ}$ & $\mathrm{R}_{45}$ & 0.77 & 0.077 & 10 & Normal \\
\hline Lankford parameter in $90^{\circ}$ & $\mathrm{R}_{90}$ & 0.90 & 0.086 & 9.6 & Lognormal \\
\hline
\end{tabular}

Tablo 9. SEM için rasgele değişken (Random variable for FEM)

\begin{tabular}{|c|c|c|c|c|}
\hline DEĞIȘKEN & ORTALAMA & S.D & DEĞișiM KATSAYISI (\%) & DAĞILIM TIPİ \\
\hline $\mathrm{F}(1)$ (ton) & 750 & 119.25 & 15.9 & Lognormal \\
\hline $\mathrm{F}(2)$ (ton) & 300 & 133.80 & 44.6 & Lognormal \\
\hline $\mathrm{F}(3)$ (ton) & 350 & 87.50 & 25.0 & Lognormal \\
\hline $\mathrm{X}(1)(\mathrm{mm})$ & 1400 & 350 & 25.0 & Lognormal \\
\hline $\mathrm{X}(2)(\mathrm{mm})$ & 1685 & 421.25 & 25.0 & Lognormal \\
\hline $\mathrm{R}(1)(\mathrm{mm})$ & 11.50 & 2.875 & 25.0 & Lognormal \\
\hline
\end{tabular}

\section{Deneysel Sonuçlar (Experimental Results)}

Bu çalışmada, geri yaylanma, buruşma ve kalınlık azalması ihtimallerini değerlendirmek için tasarım optimizasyonu metodolojisi uygulanmıştır. Olasılık tabanlı analizin performans işlevi Tablo 10 'da sonlu başarısızlık olasılıklarını ortaya koymaktadır. Otomobil panellerinde geri yaylanma, buruşma ve kalınlık azalması direk olarak kaliteyi etkilemektedir. Geri yaylanmanın fazla olması durumunda panellerin fikstürlerde kaynak edilmesinde problem oluşturacaktır. Ayrıca otomobilin dış görünüşü açısından görsel kalitede sorun teşkil edecektir. Buruşmanın fazla olması da zamanla kalıbın aşınmasına sebebiyet verecek ve kalıbın kırılmasına yol açacaktır. Kalınlı̆̆ın fazla azalması da mukavemet açısından zayıflık gösterecektir. Bu sebeple çalıșmamızda tüm performans fonksiyonları incelenmiştir. Sonuçlar Tablo 10'da gösterilmekedir.

Tablo 10.Performans fonksiyonu sonuçları (Performance function results)

\begin{tabular}{|l|c|}
\hline \multicolumn{1}{|c|}{ HATA KRITERI } & $\mathbf{p}_{\mathbf{f}} \mathbf{\%}$ \\
\hline $\mathbf{S}_{\text {Hesaplanan geri yaylanma }}$ & 2.75 \\
\hline $\mathbf{S}_{\text {Hesaplanan kalınlk azalması }}$ & 3.61 \\
\hline $\mathbf{S}_{\text {Hesaplanan burusma }}$ & 2.73 \\
\hline
\end{tabular}

Nihai bir sac kalıp kalıbı tasarımıyla sonuçlanan deterministik optimizasyon sonuçları Tablo 11 'de gösterilmektedir. Optimizasyon sonucunda $X(1), X(2), R(2), F(1), F(2)$ ve $F(3)$ değerleri belirlenmiştir.

Tablo 11. Optimum kalıp tasarımı (Optimum die design)

\begin{tabular}{|c|c|c|c|c|c|}
\hline $\begin{array}{c}\mathbf{X}(\mathbf{1}) \\
(\mathbf{m m})\end{array}$ & $\begin{array}{c}\mathbf{X}(\mathbf{2}) \\
\mathbf{( m m )}\end{array}$ & $\begin{array}{c}\mathbf{R}(\mathbf{2}) \\
\mathbf{( m m )}\end{array}$ & $\begin{array}{c}\mathbf{F}(\mathbf{1}) \\
\text { (ton) }\end{array}$ & $\begin{array}{c}\mathbf{F}(\mathbf{2}) \\
\text { (ton) }\end{array}$ & $\begin{array}{c}\mathbf{F}(\mathbf{3}) \\
(\mathbf{t o n})\end{array}$ \\
\hline 1600 & 1695 & 8 & 600 & 200 & 250 \\
\hline
\end{tabular}

Sac kalıp işleminde geri dönüşün deterministik olarak minimuma indirgenmesi, buruşma ve kalınlık azalması nedeniyle oluşturulan bu son şekil, ölçülen veri sonuçlarına kıyasla bir azalmayla sonuçlanmıştır. Bu değerler sırasıyla $\%$ 10,29 geri yaylanma, \% 9,34 kırışıklık ve \% 5,75 kalınlık azalmasıdır. Optimizasyon, her bir yapısal cevabın hem ortalama değerinde hem de standart sapmasında bir azalmayla sonuçlanmıştır. Elde edilen sonuçlar Tablo 12'de gösterilmektedir.

Tablo 12. Karşılaştırmalı sonuçlar (Compared results)

\begin{tabular}{|l|c|c|c|c|c|c|c|}
\hline \multirow{2}{*}{} & \multicolumn{2}{|c|}{$\begin{array}{c}\text { PANEL ÜZERINDEN } \\
\text { ÖLÇÜLEN DEĞER }\end{array}$} & HESAPLANAN VERI & \multicolumn{4}{c|}{$\begin{array}{c}\text { HATA } \\
\%\end{array}$} \\
\cline { 2 - 8 } & ORTALAMA & S.D & ORTALAMA & S.D & ORTALAMA & S.D \\
\hline GERI YAYLANMA & 0.418 & 11.09 & 0.461 & 12.26 & 10.29 & 10.55 \\
\hline BURUŞMA & 2.12 & 10.68 & 2.318 & 11.57 & 9.34 & 8.34 \\
\hline KALINLIK AZALMASI \% & 4 & 6.02 & 4.23 & 6.94 & 5.75 & 15.29 \\
\hline
\end{tabular}

İncelenen tüm performans fonksiyonları için deterministik optimizasyon, Tablo 13'deki bașarısızlık ihtimalinde bir düşüşe yol açmıştır. Bu sonuç oldukça önemlidir. Yaylanma, buruşma, kalınlık azalması, sac metal kalıp 
tasarımında çok önemli bir faktördür. \%13.45 geri yaylanmada, \% 12.19 kalınlık azalmasında ve \% 9.53 buruşmada hata oranı ile performans fonksiyonu analizinde panel üzerinden ölçülen deneysel sonuca göre yaklaşım göstermiştir. Optimizasyon sürecine entegre edilen olasılık tabanlı optimizasyon metodolojisi oldukça yakın bir sonuç vermiştir. Bu metodolojinin kullanılması kalıp tasarımında zamandan ve kalıp malyetinden kazanç sağlayacaktır. Bu çalıșmada ayrıca tasarım parametrelerinin etkileri araștırılmıștır. Bu tasarım parametrelerinin optimizasyon geçmişinde sac metal kalıp üzerinde ne kadar etkili olduğu hesaplanmıştır. Bu sonuçlardan yola çıkılarak tasarımcı sac metal kalıbı tasarlarken hangi parametrenin geri yaylanma, buruşma ve kalınlık azalmasına daha etki ettiğine dikkat ederek optimum kalıp tasarımı yapabilecektir. Sonuçlar Tablo 14'te gösterilmektedir.

Tablo 13. Performans fonksiyonu sonuçları (Performance function results)

\begin{tabular}{|c|c|c|c|c|}
\hline $\begin{array}{l}\text { PERFORMANS } \\
\text { FONKSIYONU }\end{array}$ & HATA KRITTERİ & $\begin{array}{c}\text { PANEL } \\
\text { ÜZERINDEN } \\
\text { ÖLÇÜLEN VERİ } \\
\text { PF (\%) } \\
\end{array}$ & 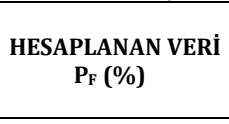 & $\begin{array}{c}\text { HATA } \\
\text { (\%) }\end{array}$ \\
\hline 2 & $S_{\text {Hesaplanan kalnnlık azalması }}$ & 4.05 & 3.61 & 12.19 \\
\hline 3 & S $_{\text {Hesaplanan buruşma }}$ & 2.99 & 2.73 & 9.53 \\
\hline
\end{tabular}

Tablo 14. Tasarım parametrelerinin etkisi (Effects of design parameters)

\begin{tabular}{|c|c|c|c|}
\hline TASARIM PARAMETRELERI & GERI YAYLANMA (\%) & BURUŞMA (\%) & KALINLIK AZALMA (\%) \\
\hline $\mathbf{X ( 1 )}$ & 46 & 57 & 41 \\
\hline $\mathbf{X ( 2 )}$ & 79 & 63 & 64 \\
\hline $\mathbf{R}(\mathbf{2})$ & 58 & 62 & 51 \\
\hline $\mathbf{F ( 1 )}$ & 51 & 12 & \\
\hline $\mathbf{F ( 2 )}$ & 67 & 78 & 6 \\
\hline $\mathbf{F ( 3 )}$ & 68 & 72 & 6 \\
\hline
\end{tabular}

\section{Sonuç ve Tartışma (Resultand Discussion)}

$\mathrm{Bu}$ çalışmada, bir otomobil yan panelinin şekillendirilebilirliğinin geliştirilmesi üç yaklaşım kullanılarak incelenmiştir. İlk yaklaşımda, çift pot çemberinin kullanılmasının yaylanma, kırışıklık ve kalınlık azaltma üzerindeki etkisi incelenmiştir. Uygun bir damgalama kuvvetine sahip çift pot çemberinin biçimlendirilebilirliğini önemli ölçüde arttırdığı gözlenmiştir. İkinci yaklaşımda, otomobil panelinin şekillendirilebilirliğinin daha da iyileştirilmesinde optimizasyon yönteminin kullanımı incelenmiştir. Üçüncü yaklaşımda, bir otomobil yan panelinin, kalıp sisteminin arızalanması olasılığına ilişkin öngörülebilirliğini geliştirmek için mevcut işe olasılık tabanlı yaklașım uygulanmıștır. Klasik tasarımda değișkenler sabit olarak belirlenir. Halbuki gerçeğinde değișkenler sabit olmayıp değerlerinin ortalaması ve standart sapması mevcuttur. Bu belirsizlikleri ortadan kaldırmak için Monte Carlo Simülasyonu kullanılmıştır. Bu uygulamada değişkenler için rastgele değerler atanarak sistemin olasılı̆̆ belirlenmiştir. Belirsizlik ve değişkenlik, kalıp sisteminin olasılık tabalı sonlu elemanlar analizinde hesaba katılmıștır. Rasgele değişkenler, baskı kuvvetini, sac malzeme özelliklerini tanımlamak için kullanılmıştır. Arıza riski, arıza modları açısından açıkça belirlenmiştir: geri yaylanma, kırışıklık ve kalınlık azaltma arızası. Optimizasyon yöntemi ile en iyi şekillendirme parametreleri incelenmiștir. Üst kalıbın pozisyonu ve çekme kalıbı, çekme kalıbı yarıçapı, üst kalıp yüzeyine uygulanan kuvvetler ve çift pot çemberi yüzeyleri proses parametreleri olarak kabul edilmiștir. Optimum değerleri bulmada SEA, YYM ve GA'nın gücü kullanılmış ve optimizasyon sürecine entegre edilmiştir. SEA'lar, D-optimal deneysel tasarım yöntemi kullanılarak tasarlanmış proses parametrelerinin kombinasyonu için gerçekleştirilmiştir. Geri yaylanma, kırışıklık ve kalınlık azaltma için tahmin edici modeller, YYM'den yararlanan SEA sonuçları kullanılarak oluşturulmuştur. YY modelleri daha sonra optimum proses parametre değerlerini bulmak için etkili bir GA ile entegre edilmiştir. Genetik Algoritma ile yapılan optimizasyon işlemi sonucunda geri yaylanma, kırışıklık ve kalınlık azalması değerlerinin önemli ölçüde azaldığı ortaya çıkmıştır. Optimizasyon sonuçlarından, optimizasyon kriterleri değiştiğinde X(2), R(2) ve F(1) 'in işlem parametrelerinin değişmediği görülmüştür. $F(3)$ çok az değişmiştir. Ancak, X(1) ve F(2) belirtilen oluşturma kriterlerine göre değişmektedir. Sonuç olarak, bu çalışmada önerilen optimizasyon metodolojisi, otomotiv endüstrisinde şekillendirme işlemlerinde en iyi şekillendirilebilirlik koşullarını geliştirmek ve belirlemek için başarıyla kullanılabilir.

\section{Teşekkür (Acknowledgement)}

Bu çalışma FORD OTOSAN TÜRKIYE Takım ve Kalıp ve Prototip İmalat Bölümü için yapılmıştır, Yazar tasarım sürecinde gerekli verileri sağlayan Ferit Fırat'a teşekkür eder.

\section{Çıkar Çatışması (Conflict of Interest)}

Yazar tarafından herhangi bir çıkar çatışması beyan edilmemiștir. No conflict of interest was declared by the author. 


\section{Kaynaklar (References)}

Cao, J., Boyce, M., 1997. Wrinkling behavior of rectangular plates under lateral constraint, International Journal of Solids and Structure, 34, $153-176$.

Cao, J., Karallis, A., Ostrowski, M., 1997. Prediction of flange wrinkles in deep drawing, Advanced methods in material processing defects, 301-310.

Cao, J., Wang, X., 1999. An analytical model for plate wrinkling under tri-axial loading and its application, International Journal of Mechanical Sciences, 42(3), 617-633.

Choi, T.,H., Huh, H., 1997. Draw-bead Simulation by an Elasto-plastic Finite Element Method with Directional Reduced Integration, Journal of Material Processing Technology, 63, 666-671.

Gasper, G., Tomaz, P., Karl, K., 2002. Optimization of sheet metal forming process by use of numerical simulations, Journal of Material Processing Technology, 130-131, 54-59.

Ghouati, O., Lenoir, H, Gelin, J.C., 1999. Optimisation techniques for the drawing of sheet metal parts, Proceedings of the Fourth International Conference on Numerical Simulations NUMISHEET' 99, 293-298.

Demir, İ., Kayabasi, O., Ekici, B., 2008. Probabilistic design of sheet-metal die by finite element method, Materials and Design, 29 (3), 721-727.

Hallquist, J.O., 2003. LS-DYNA Theoretical Manual', Livermore Software Technology Corporation, Livermore, CA, USA.

Hillmann, M., 1999. Optimisation of sheet metal forming processes using simulation programs, Proceedings of the Fourth International Conference on Numerical Simulations NUMISHEET'99, 287-292.

Jansson, T., Andersson, A., Nilsson, L., 2005. Optimization of draw-in for an automotive sheet metal part An evaluation using surrogate models and response surface, Journal of Material Processing Technology, 159, 426-434

Myers, R.H., 1995. Montgomery DC,, Response surface methodology process and product optimization using designed experiments, John Wiley and Sons, Inc,, New York, USA.

Ohata, T., Katayama, T., Nakamachi, E., Nakamura, Y., Kawahara, H., 1999. Improvement of optimum process design system by numerical simulation-discretized optimisation method, Proceedings of the Fourth International Conference on Numerical Simulations NUMISHEET'99, 293-298.

Personal Communication, 2005. FORD OTOSAN TURKEY Tool\&Die and Prototype Manufacturing Department Turkey.

Prasad, Y., Somasundaram, S., 1993. Mathematical model for bend allowance calculation in automated sheet-metal bending, Journal of Materials Process Technology, 39 (3), 337-356.

Radha, K. L., Vikas, K. C., Dwivedi, S.K., 2018. Study of factors affecting Springback in Sheet Metal Forming and Deep Drawing Process Materials Today: Proceedings 5, 4353-4358.

Stander, N., Eggleston, T., Craig, K., Roux, W., 2004. LS-OPT User's Manual, Livermore Software Technology Corporation, Livermore, CA, USA.

Wang, X., Cao J., 1998. An analytical model for predicting flange wrinkling in deep drawing, Transactions of NAMRI SME, XXVI:25, 30.

Wang, C., Kinzel, G., Altan T., 1993. Mathematical modeling of planestrain bending of sheet and plate, Journal of Materials Process Technology, 39 (3), 279-304.

Xiaoxiang, S., Jun, C., Yinghong P., Xueyu R., 2004. A new approach of die shape optimization for sheet metal forming process, Journal of Material Processing Technology, 152, 35-42. 